\title{
Interactions among variants in TXA2R, P2Y12 and Research Paper associated with carotid plaque vulnerability in Chinese population
}

\author{
Xingyang $\mathrm{Yi}^{1}$, Jing Lin ${ }^{2, *}$, Hua $\mathrm{Luo}^{3, *}$, Ju Zhou ${ }^{1}$, Qiang Zhou ${ }^{2}$, Yanfen Wang ${ }^{1}$ and \\ Chun Wang ${ }^{1}$ \\ ${ }^{1}$ Department of Neurology, The People's Hospital of Deyang City, Deyang 618000, Sichuan, China \\ ${ }^{2}$ Department of Neurology, The Third Affiliated Hospital of Wenzhou Medical University, Wenzhou 325200, Zhejiang, China \\ ${ }^{3}$ Department of Neurology, The Affiliated Hospital of Southwest Medical University, Luzhou 646000, Sichuan, China \\ "These authors contributed equally to this work \\ Correspondence to: Jing Lin, email: 22350277@qq.com, yixingyang64@126.com \\ Hua Luo, email: Izlh@sina.com \\ Keywords: ischemic stroke; carotid atherosclerosis; carotid plaque vulnerability; genetic polymorphism; platelet activation \\ Received: December 04, $2017 \quad$ Accepted: March 12, $2018 \quad$ Published: April 03, 2018 \\ Copyright: Yi et al. This is an open-access article distributed under the terms of the Creative Commons Attribution License 3.0 (CC \\ BY 3.0), which permits unrestricted use, distribution, and reproduction in any medium, provided the original author and source are \\ credited.
}

\section{ABSTRACT}

Purpose: The associations between variants in platelet activation-relevant genes and carotid plaque vulnerability are not fully understood. The aim of the present study was to investigate the associations of the variants in platelet activation-relevant genes and interactions among these variants with carotid plaque vulnerability.

Results: There were no significant differences in the frequencies of genotypes of the 11 variants between patients and controls. Among 396 patients, 102 patients had not carotid plaque, 106 had VP, and 188 had SP. The 11 variants were not independently associated with risk of carotid plaque vulnerability after adjusting for potential confounding variables. However, the GMDR analysis showed that there were synergistic effects of gene-gene interactions among TXA2Rr S1131882, GPIIIa rs2317676 and P2Y12 rs16863323 on carotid plaque vulnerability. The high-risk interactions among the three variants were associated with high platelet activation, and independently associated with the risk of carotid plaque vulnerability.

Methods: Eleven variants in platelet activation-relevant genes were examined using mass spectrometry methods in 396 ischemic stroke patients and 291controls. Platelet-leukocyte aggregates and platelet aggregation were also measured. Carotid plaques were assessed by B-mode ultrasound. According to the results of ultrasound, the patients were stratified into three groups: non-plaque group, vulnerable plaque (VP) group and stable plaque (SP) group. Furthermore, gene-gene interactions were analyzed using generalized multifactor dimensionality reduction (GMDR) methods.

Conclusions: The rs1131882, rs2317676, and rs16863323 three-loci interactions may confer a higher risk of carotid plaque vulnerability, and might be potential markers for plaque instability.

\section{INTRODUCTION}

Stroke is one of leading causes of mortality and disability in China [1,2]. Carotid atherosclerosis is a major risk factor for ischemic stroke (IS). Carotid plaque rupture or vulnerable lesions may obstruct the blood vessels of the brain by atherothrombosis or emboli $[3,4]$.The degree of carotid stenosis alone may not be sufficient to evaluate the risk of stroke [5]. The cholucent plaque or ulcerative plaque in carotid may play a more important role in the occurrence of cerebrovascular events than carotid stenosis $[5,6]$. Therefore, identifying novel etiologies of carotid 
plaque vulnerability, including the genetic etiology is very important for preventing stroke [7]. However, up to date, such a genetic etiology has not been fully understood.

Carotid plaque vulnerability may be assessed by B-mode ultrasound or high-resolution magnetic resonance imaging (HR-MRI), HR-MRI may provide more information regarding plaque composition and morphology [8]. However, HR-MRI is not routinely used to assess carotid plaque vulnerability in China, because of expensive cost of HR-MRI assessment. Clinically, carotid ultrasound is a well method for visualizing and quantifying carotid atherosclerotic lesions and its vulnerability, and echo-lucent lipid-rich plaques are associated with more complications than that of mixed or calcified plaques $[9,10]$. Heterogeneous plaques were reportedly associated with intraplaque hemorrhage and ulceration [11].

Atherosclerosis is a complex inflammatory disorder. Platelet activation, inflammation and endothelial functionplay key roles in the atherosclerosis pathogenesis. Gardener et al. [12] have reported that the variations of genes involved in endothelial function and inflammation are associated with carotid plaque stability in a Dominican population. Our previous studies showed that genetic variants of Cytochrome P450 and cyclooxygenase pathway genes were associated with plaque stability $[13,14]$. Platelet aggregation and platelet-leukocyte aggregates play a key role in thrombogenesis and IS $[15,16]$, antiplatelet therapy is recommended for prevention of IS [17]. Platelet activation is also associated with the pathophysiology of atherogenesis [18, 19]. Prostaglandin $\mathrm{H}$ can be metabolized by thromboxane synthase (TXAS) into thromboxanes A2 (TXA2), a potent vasoconstrictor and platelet activator. TXA2 bind to its receptor TXA2R are associated with higher platelet activation [13]. Platelet membranes receptors (P2Y1, P2Y12) and fibrinogen receptor [glycoprotein IIIa (GPIIIa) and glycoprotein IIb (GPIIb) are the final common pathway of platelet activation, aggregation, and adhesion $[20,21]$, and play important roles in the process of platelet activation [20]. Previous studies have revealed that single nucleotide polymorphisms (SNPs) in TXA2R, P2Y1, P2Y12 and GPIIb/IIIa genes significantly increase the risk for IS [13, 22], and influence response to antiplatelet drugs [23-25]. However, the associations between variants in platelet activation-relevant genes and plaque vulnerability have not well been underscored. Furthermore, few studies investigated the effect of gene-gene interactions among platelet activation-relevant genes on carotid plaque vulnerability using generalized multifactor dimensionality reduction (GMDR) method [26].

In this study, we hypothesized that the platelet activation-relevant genetic variants and these variants interactions were associated with the risk for carotid plaque vulnerability by influencing platelet activation. To test this hypothesis, we evaluated 11 variants from platelet activation-relevant genes and platelet activation in 396 IS patients and 291 controls to determine the associations of these variants and interactions among these variants with carotid plaque vulnerability in Chinese population.

\section{RESULTS}

\section{Clinical characteristics, genotype distributions and platelet activation in patients and controls}

Diabetes mellitus and hypertension were more frequent in patients than controls (Table1). However, there were no significant differences in other risk factors between the two groups (Table 1). The genotype distributions of the 11 variants were in Hardy-Weinberg equilibrium $(P>0.05)$, and there were no significant differences in genotype distributions of the 11 variants between patients and controls (Table 1). The arachidonic acid (AA) or adenosine diphosphate (ADP)-induced platelet aggregation and platelet-leukocyte aggregates were higher in patients compared with controls (Table 1).

\section{Clinical characteristics in patients with and without carotid plaque}

Among 396 patients (276 were atherothrombotic [AT] stroke, and 120 were small artery disease [SAD] stroke), 294 (74.2\%) patients had plaque (188 had stable plaque [SP], 106 had vulnerable plaque [VP]). Diabetes mellitus, hypertension, AT stroke, and hyperlipidemia were more frequent in patients with plaque than those patients without plaque. Compared with patients with SP, the frequency of hypertension, diabetes mellitus and hyperlipidemia was higher in patients with VP (Table 2). The platelet-leukocyte aggregates and platelet aggregation were significantly higher in patients with VP compared with patients without plaque or with SP (Table 2).

\section{Genotype distributions in patients with and without plaque}

The frequency of TXA2R rs1131882TT, TXAS1 rs2267679TT, TXAS1 rs41708TT, P2Y12 rs16863323T, and GPIIIa rs2317676GG was higher in patients with plaque than without plaque, or in patients with VP than with SP using a single-locus analytical approach (Table 3). However, the genotype of rs1131882TT, rs2267679TT, rs41708TT, rs16863323TT, and rs2317676GG was not independently associated with risk of VP after adjusting for potential confounding variables.

\section{Gene-gene interaction and its association with carotid plaque vulnerability}

The associations of gene-gene interactions among the 11 variants with carotid plaque vulnerability were investigated using GMDR approach (Table 4). The best model for VP including rs1131882, rs2317676 and 
Table 1: Clinical characteristics and genotype distributions in patients and controls $(n, \%)$

\begin{tabular}{|c|c|c|c|}
\hline & $\begin{array}{l}\text { Stroke patients } \\
\quad(n=396)\end{array}$ & $\begin{array}{l}\text { Controls } \\
(n=291)\end{array}$ & $P$ value \\
\hline Age (years) & $68.4 \pm 11.8$ & $66.9 \pm 10.9$ & 0.083 \\
\hline $\operatorname{Men}(n, \%)$ & $235(59.3)$ & $165(56.7)$ & 0.473 \\
\hline Hypertension $(n, \%)$ & $287(72.5)$ & $130(44.7)$ & $<0.001$ \\
\hline Diabetes mellitus $(n, \%)$ & $138(34.8)$ & $73(25.1)$ & 0.006 \\
\hline Body mass index $\left(\mathrm{kg} / \mathrm{m}^{2}\right)$ & $24.1 \pm 2.3$ & $23.9 \pm 2.5$ & 0.289 \\
\hline Current smoking $(n, \%)$ & $160(40.4)$ & $118(40.5)$ & 0.998 \\
\hline $\begin{array}{l}\text { Previous or ongoing drug } \mathrm{t} \\
\text { Antihypertensive drugs } \\
\text { Hypoglycemic drugs } \\
\text { Statins } \\
\text { Antiplatelet drugs }\end{array}$ & $\begin{array}{l}121(30.6) \\
95(23.9) \\
51(12.9) \\
83(20.9)\end{array}$ & $\begin{array}{l}75(25.8) \\
58(19.9) \\
32(11.0) \\
47(16.2)\end{array}$ & $\begin{array}{l}0.201 \\
0.225 \\
0.398 \\
0.124\end{array}$ \\
\hline $\begin{array}{l}T X A 2 R(\mathrm{rs} 1131882) \\
\text { CC } \\
\text { CT } \\
\text { TT }\end{array}$ & $\begin{array}{c}135(34.1) \\
184(46.5) \\
77(19.4)\end{array}$ & $\begin{array}{c}100(34.4) \\
135(46.4) \\
56(19.2)\end{array}$ & 0.978 \\
\hline $\begin{array}{l}\text { TXAS1 (rs194149) } \\
\text { AA } \\
\text { AG } \\
\text { GG }\end{array}$ & $\begin{array}{c}65(16.4) \\
197(49.7) \\
134(33.8)\end{array}$ & $\begin{array}{c}40(13.7) \\
164(56.4) \\
87(29.9)\end{array}$ & 0.193 \\
\hline $\begin{array}{l}\text { TXAS1 (rs2267679) } \\
\text { CC } \\
\text { CT } \\
\text { TT }\end{array}$ & $\begin{array}{c}11(2.8) \\
91(23.0) \\
294(74.2)\end{array}$ & $\begin{array}{c}1(0.3) \\
47(16.2) \\
243(83.5)\end{array}$ & 0.106 \\
\hline $\begin{array}{l}\text { TXAS1 (rs41708) } \\
\text { GG } \\
\text { GT } \\
\text { TT }\end{array}$ & $\begin{array}{c}239(60.4) \\
110(27.8) \\
47(11.9)\end{array}$ & $\begin{array}{c}177(60.8) \\
92(31.6) \\
22(7.6)\end{array}$ & 0.764 \\
\hline $\begin{array}{l}P 2 Y 1(\mathrm{rs} 701265) \\
\text { AA } \\
\text { AG } \\
\text { GG }\end{array}$ & $\begin{array}{c}217(54.8) \\
119(30.0) \\
60(15.2)\end{array}$ & $\begin{array}{c}168(57.7) \\
85(29.2) \\
38(13.1)\end{array}$ & 0.482 \\
\hline $\begin{array}{l}\text { P2Y1 (rs1439010) } \\
\text { AA } \\
\text { AG } \\
\text { GG }\end{array}$ & $\begin{array}{c}215(54.3) \\
122(30.8) \\
59(14.9)\end{array}$ & $\begin{array}{c}169(58.1) \\
84(28.8) \\
38(13.1)\end{array}$ & 0.343 \\
\hline $\begin{array}{l}P 2 Y 1(\mathrm{rs} 1371097) \\
\text { CC } \\
\text { CT } \\
\text { TT }\end{array}$ & $\begin{array}{c}208(52.5) \\
125(31.6) \\
63(15.9)\end{array}$ & $\begin{array}{c}170(58.4) \\
87(29.9) \\
34(11.7)\end{array}$ & 0.265 \\
\hline $\begin{array}{l}P 2 Y 12(\mathrm{rs} 16863323) \\
\text { CC } \\
\text { CT } \\
\text { TT }\end{array}$ & $\begin{array}{l}121(30.6) \\
131(33.1) \\
144(36.4)\end{array}$ & $\begin{array}{c}73(25.1) \\
102(35.1) \\
116(39.8)\end{array}$ & 0.513 \\
\hline $\begin{array}{l}\text { P2Y12 (rs9859538) } \\
\text { GG } \\
\text { AG } \\
\text { AA }\end{array}$ & $\begin{array}{c}273(68.9) \\
87(22.0) \\
36(9.1)\end{array}$ & $\begin{array}{c}215(73.9) \\
58(19.9) \\
18(6.2)\end{array}$ & 0.327 \\
\hline
\end{tabular}




$\begin{array}{lccc}\text { GPIIIa (rs2317676) } & & \\ \text { AA } & 242(61.1) & 186(63.9) & 0.397 \\ \text { AG } & 106(26.8) & 73(25.1) & 32(11.0) \\ \text { GG } & 48(12.1) & & 0.473 \\ \text { GPIIIa (rs11871251) } & 151(38.1) & 96(33.0) & \\ \text { AA } & 135(34.1) & 105(36.1) & <0(30.9) \\ \text { AG } & 110(27.8) & & <0.001 \\ \text { GG } & & 82.2 \pm 13.8 & <0.001 \\ \text { Platelet aggregation (\%) } & 87.9 \pm 15.6 & 83.5 \pm 12.9 & <0.001 \\ \text { AA-induced } & 88.1 \pm 17.2 & & <0.001 \\ \text { ADP-induced } & & 21.6 \pm 7.1 & <0.001 \\ \text { Platelet-leukocyte aggregates }(\%) & 24.3 \pm 7.3 & 22.1 \pm 6.2 & 0.007 \\ \text { Leukocyte } & 24.2 \pm 7.2 & 21.8 \pm 5.3 & \\ \text { Neutrophil } & 24.9 \pm 6.8 & 22.3 \pm 6.2 & \\ \text { Monocyte } & 23.8 \pm 7.2 & & \\ \text { Lymphocyte } & & & \\ \end{array}$

Table 2: Clinical characteristics, platelet aggregation and platelet-leukocyte aggregates in patients with or without carotid plaque

\begin{tabular}{|c|c|c|c|c|}
\hline Characteristics & $\begin{array}{c}\text { VP } \\
(n=106)\end{array}$ & $\begin{array}{c}\text { SP } \\
(n=188)\end{array}$ & $\begin{array}{l}\text { Non- plaque } \\
(n=102)\end{array}$ & $P$ value \\
\hline Age (years) & $68.6 \pm 10.8$ & $68.1 \pm 11.9$ & $67.9 \pm 11.9$ & 0.535 \\
\hline $\operatorname{Men}(n, \%)$ & $62(58.5)$ & $112(59.6)$ & $61(59.8)$ & 0.912 \\
\hline Hypertension $(n, \%)$ & $95(89.6)$ & $140(74.5)$ & $52(51.0)$ & $<0.001$ \\
\hline Diabetes mellitus ( $n, \%)$ & $50(47.2)$ & $64(34.0)$ & $24(23.5)$ & 0.008 \\
\hline Previous MI $(n, \%)$ & $1(0.9)$ & $2(1.1)$ & $2(2.0)$ & 0.986 \\
\hline Current smoking $(n, \%)$ & $45(42.5)$ & $75(39.9)$ & $40(39.2)$ & 0.898 \\
\hline Alcohol intake $(n, \%)$ & $49(46.2)$ & $86(45.7)$ & $45(44.1)$ & 0.978 \\
\hline Body mass index (kg/m2) & $24.1 \pm 2.5$ & $24.0 \pm 2.6$ & $23.9 \pm 2.6$ & 0.582 \\
\hline Hyperlipidemia ( $n, \%)$ & $82(77.4)$ & $124(65.9)$ & $56(54.9)$ & 0.004 \\
\hline Fasting blood glucose (mM) & $7.1 \pm 2.1$ & $7.0 \pm 2.1$ & $6.9 \pm 2.4$ & 0.315 \\
\hline Hemoglobin A1c (\%) & $6.2 \pm 1.4$ & $6.1 \pm 1.4$ & $6.0 \pm 1.5$ & 0.136 \\
\hline Homocysteine (mM) & $14.3 \pm 4.3$ & $13.9 \pm 4.2$ & $13.5 \pm 4.1$ & 0.138 \\
\hline $\begin{array}{l}\text { Stroke subtype }(n, \%) \\
\text { AT stroke } \\
\text { SAD stroke }\end{array}$ & $\begin{array}{l}78(73.6) \\
28(26.4)\end{array}$ & $\begin{array}{c}135(71.8) \\
53(28.2)\end{array}$ & $\begin{array}{l}63(61.8) \\
39(38.2)\end{array}$ & $\begin{array}{c}0.046 \\
-\end{array}$ \\
\hline $\begin{array}{l}\text { Previous or ongoing drug } \\
\text { treatments }(n, \%) \\
\text { Antihypertensive drugs } \\
\text { Hypoglycemic drugs } \\
\text { Statins } \\
\text { Antiplatelet drugs }\end{array}$ & $\begin{array}{l}32(30.2) \\
29(27.4) \\
14(13.2) \\
21(19.8)\end{array}$ & $\begin{array}{l}57(30.3) \\
47(25.0) \\
25(13.3) \\
39(20.8)\end{array}$ & $\begin{array}{l}32(31.4) \\
19(18.6) \\
12(11.8) \\
23(22.6)\end{array}$ & $\begin{array}{l}0.893 \\
0.127 \\
0.336 \\
0.875\end{array}$ \\
\hline \multicolumn{5}{|l|}{ Platelet aggregation (\%) } \\
\hline $\begin{array}{l}\text { AA-induced } \\
\text { ADP-induced }\end{array}$ & $\begin{array}{l}91.2 \pm 11.4 \\
89.7 \pm 12.1\end{array}$ & $\begin{array}{l}86.9 \pm 10.4 \\
86.1 \pm 11.5\end{array}$ & $\begin{array}{l}84.6 \pm 11.7 \\
84.7 \pm 10.8\end{array}$ & $\begin{array}{l}0.002 \\
0.008\end{array}$ \\
\hline \multicolumn{5}{|c|}{ Platelet-leukocyte aggregates (\%) } \\
\hline Leukocyte & $28.1 \pm 6.7$ & $23.8 \pm 5.4$ & $22.8 \pm 7.2$ & $<0.001$ \\
\hline Neutrophil & $27.2 \pm 6.8$ & $22.9 \pm 7.1$ & $22.2 \pm 6.4$ & $<0.001$ \\
\hline
\end{tabular}




$\begin{array}{lllll}\text { Monocyte } & 26.9 \pm 5.5 & 22.3 \pm 6.3 & 21.8 \pm 4.7 & <0.001 \\ \text { Lymphocyte } & 26.4 \pm 5.6 & 22.4 \pm 7.5 & 21.8 \pm 5.8 & <0.001\end{array}$

VP, vulnerable plaque; SP, stable plaque; MI, myocardial infarction; AT, atherothrombotic; SAD, small artery disease; AA, arachidonic acid; ADP, adenosine diphosphate.

Table 3: Genotype distribution comparison among the three groups $(n, \%)$

\begin{tabular}{|c|c|c|c|c|}
\hline & $\begin{array}{c}\text { VP } \\
(n=106) \\
\end{array}$ & $\begin{array}{c}\mathrm{SP} \\
(n=188) \\
\end{array}$ & $\begin{array}{c}\text { Non- plaque } \\
(n=102) \\
\end{array}$ & $P$ value \\
\hline \multicolumn{5}{|c|}{$T X A 2 R(\mathrm{rs} 1131882)$} \\
\hline $\mathrm{CC}$ & $28(26.4)$ & $65(34.6)$ & $42(41.2)$ & \multirow[t]{3}{*}{0.009} \\
\hline CT & $47(44.3)$ & $87(46.3)$ & $50(49.0)$ & \\
\hline TT & $31(29.2)$ & $36(19.1)$ & $10(9.8)$ & \\
\hline \multicolumn{5}{|c|}{ TXAS1 (rs2267679) } \\
\hline $\mathrm{CC}$ & $2(1.9)$ & $8(4.3)$ & $1(0.9)$ & \multirow[t]{3}{*}{$<0.001$} \\
\hline CT & $14(13.2)$ & $42(22.3)$ & $35(34.3)$ & \\
\hline TT & $90(84.9)$ & $138(73.4)$ & $66(64.7)$ & \\
\hline \multicolumn{5}{|c|}{ TXAS1 (rs194149) } \\
\hline AA & $17(16.0)$ & $33(17.5)$ & $15(14.7)$ & \multirow[t]{3}{*}{0.916} \\
\hline AG & $53(50.0)$ & $90(47.9)$ & $54(52.9)$ & \\
\hline GG & $36(34.0)$ & $65(34.6)$ & $33(32.4)$ & \\
\hline \multicolumn{5}{|c|}{ TXAS1 (rs41708) } \\
\hline GG & $53(50.0)$ & $114(60.6)$ & $72(70.6)$ & \multirow[t]{3}{*}{$<0.001$} \\
\hline GT & $30(28.3)$ & $55(29.3)$ & $25(24.5)$ & \\
\hline TT & $23(21.7)$ & $19(10.1)$ & $5(4.9)$ & \\
\hline \multicolumn{5}{|c|}{ P2Y1 (rs701265) } \\
\hline AA & $58(54.7)$ & $102(54.3)$ & $57(55.9)$ & \multirow[t]{3}{*}{0.986} \\
\hline $\mathrm{AG}$ & $32(30.2)$ & $57(30.3)$ & $30(29.4)$ & \\
\hline GG & $16(15.1)$ & $29(15.4)$ & $15(14.7)$ & \\
\hline \multicolumn{5}{|c|}{$P 2 Y 1$ (rs1439010) } \\
\hline AA & $56(52.8)$ & $103(54.8)$ & $56(54.9)$ & \multirow[t]{3}{*}{0.967} \\
\hline AG & $34(32.1)$ & $57(30.3)$ & $31(30.4)$ & \\
\hline GG & $16(15.1)$ & $28(14.9)$ & $15(14.7)$ & \\
\hline \multicolumn{5}{|c|}{ P2Y1 (rs1371097) } \\
\hline $\mathrm{CC}$ & $53(50.0)$ & $100(53.2)$ & $55(53.9)$ & \multirow[t]{3}{*}{0.926} \\
\hline $\mathrm{CT}$ & $35(33.0)$ & $59(31.4)$ & $31(30.4)$ & \\
\hline TT & $18(17.0)$ & $29(15.4)$ & $16(15.7)$ & \\
\hline \multicolumn{5}{|c|}{ P2Y12 (rs16863323) } \\
\hline $\mathrm{CC}$ & $26(24.5)$ & $55(29.3)$ & $40(39.2)$ & \multirow[t]{3}{*}{0.022} \\
\hline $\mathrm{CT}$ & $30(28.3)$ & $65(34.5)$ & $36(35.3)$ & \\
\hline TT & $50(47.2)$ & $68(36.2)$ & $26(25.5)$ & \\
\hline \multicolumn{5}{|c|}{ P2Y12 (rs9859538) } \\
\hline GG & $72(67.9)$ & $131(69.7)$ & $70(68.6)$ & \multirow[t]{3}{*}{0.946} \\
\hline $\mathrm{AG}$ & $23(21.7)$ & $40(21.3)$ & $24(23.5)$ & \\
\hline AA & $11(10.4)$ & $17(9.0)$ & $8(7.8)$ & \\
\hline \multicolumn{5}{|c|}{ GPIIIa (rs2317676) } \\
\hline AA & $62(58.5)$ & $114(60.6)$ & $66(64.7)$ & \multirow[t]{3}{*}{0.003} \\
\hline AG & $21(19.8)$ & $54(28.7)$ & $31(30.4)$ & \\
\hline GG & $23(21.7)$ & $20(10.6)$ & $5(4.9)$ & \\
\hline \multicolumn{5}{|c|}{ GPIIIa (rs11871251) } \\
\hline AA & $40(37.7)$ & $72(38.3)$ & 39 (38.2) & \multirow[t]{3}{*}{0.953} \\
\hline AG & $35(33.0)$ & $64(34.0)$ & $36(35.3)$ & \\
\hline GG & $31(29.2)$ & $52(27.7)$ & $27(26.5)$ & \\
\hline
\end{tabular}

VP, vulnerable plaque; SP, stable plaque. 
rs16863323 scored 10/10 for cross-validation consistency and $9 / 10$ for sign test after adjustment with covariates $(P=0.015$, Table 4$)$. The $P$ value for prediction error was 0.028 for GMDR using permutation testing.

\section{Different genotype combinations and the risk of carotid plaque vulnerability}

Subsequently, we assessed the associations of different genotype combinations among rs1131882, rs2317676, and rs16863323 with VP risk. Compared to patients harboring rs1131882CC, rs2317676AA, and rs16863323CC (wildtype genotypes), the relative risk of different genotype combinations of rs1131882, rs2317676 and rs16863323 was analyzed. The three genotype combinations making larger contributions to VP risk were rs1131882TT, rs2317676GG and rs16863323TT; rs1131882TT, rs2317676AG and rs16863323CT; and rs1131882TT, rs2317676GG and rs16863323CT/TT (Table 5), and were defined as the highrisk interactions. The other genotype combinations among rs1131882, rs2317676, and rs16863323 did not reach cut-off significance level of 0.05 , and were defined as the low-risk interactions (Table 5).

\section{Logistic regression analysis of risk of carotid plaque vulnerability}

The relative risk for VP conferred by different genotype combinations among rs1131882, rs2317676 and rs16863323 was assessed using multivariate logistic regression analysis. The high-risk interactions were assigned as one, and the low-risk interactions were assigned as zero. The other variables that showed a significant association with VP $(P<0.05)$ on univariate analysis, and previous statins or antiplatelet treatments were also entered in the multivariate logistic regression model. The results revealed that the high-risk interactions were independently associated with risk for VP after adjustment with covariates (OR, 2.61, 95\% CI 1.33-7.98, $P=0.005$, Table 6).

\section{Effect of the high-risk interactive genotypes on platelet activation}

There were no significant differences in AA or ADP - induced platelet aggregation and platelet-leukocyte aggregates among genotypes of the 11 variants on admission. However, the platelet-leukocyte aggregates and platelet aggregation were significantly higher in patients carrying the high-risk interactive genotypes than those patients without carrying the high-risk interactive genotypes (Table 7).

\section{DISCUSSION}

Platelet activation was associated the pathophysiology of atherogenesis and IS [15, 16, 18, 19]. Our previous studies have administrated that the variants of platelet activationrelevant genes (TXA2R, GPIIIa, P2Y12, P2Y1, TXAS1) not only increase the risk for IS, but also are associated with response to antiplatelet drugs and clinical adverse outcomes after IS [13, 22, 25, 27, 28]. However, the associations of the variants in platelet activation-relevant genes with carotid plaque vulnerability were not fully understood. Our current results showed the frequency of TXA2R rs1131882TT, TXAS1 rs2267679TT, TXAS1 rs41708TT, P2Y12 rs16863323TT, and GPIIIa rs2317676GG were higher in patients with VP than patients with SP or without plaque using a single-locus analytical approach. After adjusting for potential confounding variables, these genotypes were not independently associated with risk of VP. However, we observed significant gene-gene interactions among variants of rs1131882, rs2317676 and rs16863323 using the GMDR approach. The high-risk interactions of the three variants were associated with platelet activation, and independently associated with the risk for VP.

These indicated that single-locus analytical approach (such as linkage analysis) seems unsuitable for genetic etiology of carotid plaque vulnerability. Atherosclerosis is a common complex disease, and does not follow Mendelian pattern of inheritance [29]. It is possible that genes contribute to the complex diseases only by interactions with other genes, and the effects of individual variant may be too small to be detected [30]. Our previous studies have administrated that the GMDR analysis may be helpful to understand complex genetic etiology of IS [22, 25, 27, 28]. However, few studies used the GMDR approach to investigate complex genetic risk for carotid plaque vulnerability.

The most noteworthy finding in current study was that there were interesting synergistic effects of gene-gene interactions on the risk of carotid plaque vulnerability and platelet activation via the GMDR methods. Variants among rs1131882, rs2317676, and rs16863323 were identified to interact together to influence the risk for carotid plaque vulnerability. The risk of carotid plaque vulnerability was increased by 2.61 -fold in patients carrying the high-risk interactive genotypes than those without carrying the highrisk interactive genotypes.

Despite the pathophysiological significance of the interactions of the three variants is unclear, these findings are very interesting. Atherosclerosis is associated with chronic inflammatory. Platelet activation may play a key role in the pathophysiology of atherogenesis [18, 19]. The present results showed that the platelet-leukocyte aggregates and platelet aggregation were higher in patients with VP than patients without plaque or with SP, or in patients carrying high-risk interactive genotypes than those without carrying the high-risk interactive genotypes. Thus, one possible explanation for the three variants interactions is that they together participate in platelet activation. TXA2R and TXAS are important components in TXA2 function, and binding of TXA2 to TXA2R is crucial for 
Table 4: Comparison of the best models, prediction accuracies, cross-validation consistencies, and $P$ values for vulnerable plaque identified by GMDR

\begin{tabular}{|c|c|c|c|c|c|c|c|c|}
\hline \multicolumn{3}{|l|}{ Best model $^{*}$} & \multicolumn{2}{|c|}{$\begin{array}{l}\text { Training balanced } \\
\text { accuracy }\end{array}$} & $\begin{array}{l}\text { Testing balanced } \\
\text { accuracy }\end{array}$ & \multicolumn{2}{|c|}{$\begin{array}{c}\text { Cross-validation } \\
\text { consistency }\end{array}$} & Sign test $(P)$ \\
\hline \multicolumn{3}{|l|}{1} & \multicolumn{2}{|l|}{0.397} & 0.612 & \multicolumn{2}{|c|}{$6 / 10$} & $8(0.423)$ \\
\hline \multicolumn{3}{|l|}{1,2} & \multicolumn{2}{|l|}{0.525} & 0.605 & \multicolumn{2}{|c|}{$9 / 10$} & $8(0.342)$ \\
\hline \multicolumn{3}{|l|}{$1,2,3$} & \multicolumn{2}{|l|}{0.687} & 0.672 & \multicolumn{2}{|c|}{$10 / 10$} & $9(0.015)$ \\
\hline \multicolumn{3}{|l|}{$1,2,3,4$} & \multicolumn{2}{|l|}{0.585} & 0.612 & \multicolumn{2}{|c|}{$7 / 10$} & $7(0.325)$ \\
\hline \multicolumn{3}{|l|}{$1,2,3,4,5$} & \multicolumn{2}{|l|}{0.575} & 0.512 & \multicolumn{2}{|c|}{$8 / 10$} & $6(0.642)$ \\
\hline \multicolumn{3}{|l|}{$1,2,3,4,5,6$} & \multicolumn{2}{|l|}{0.622} & 0.479 & \multicolumn{2}{|c|}{$7 / 10$} & $8(0.576)$ \\
\hline \multicolumn{3}{|c|}{$1,2,3,4,5,6,7$} & \multicolumn{2}{|l|}{0.499} & 0.526 & \multicolumn{2}{|c|}{$8 / 10$} & $5(0.734)$ \\
\hline \multicolumn{3}{|c|}{$1,2,3,4,5,6,7,8$} & \multicolumn{2}{|l|}{0.613} & 0.611 & \multicolumn{2}{|c|}{$7 / 10$} & $6(0.412)$ \\
\hline \multicolumn{3}{|c|}{$1,2,3,4,5,6,7,8,9$} & \multicolumn{2}{|l|}{0.598} & 0.572 & \multicolumn{2}{|c|}{$6 / 10$} & $7(0.665)$ \\
\hline \multicolumn{3}{|c|}{$\begin{array}{l}1,2,3,4,5,6,7,8,9,10 \\
1,2,3,4,5,6,7,8,9,10,11\end{array}$} & \multicolumn{2}{|l|}{$\begin{array}{l}0.613 \\
0.504\end{array}$} & $\begin{array}{l}0.476 \\
0.644\end{array}$ & \multicolumn{2}{|c|}{$8 / 10$} & $\begin{array}{l}5(0.684) \\
6(0.337)\end{array}$ \\
\hline \multicolumn{9}{|c|}{$\begin{array}{l}\text { "rs1131882, rs2317676, rs16863323, rs194149, rs2267679, rs41708, rs701265, rs1439010, rs1371097, rs9859538, } \\
\text { rs11871251 are symbolized as } 1-11, \text { respectively. } \\
\text { GMDR, generalized multifactor dimensionality reduction. }\end{array}$} \\
\hline \multicolumn{9}{|c|}{ Table 5: Associations between genotype combinations and vulnerable plaque } \\
\hline rs1131882 & $\mathrm{CC}$ & $\mathrm{TT}$ & TT & $\mathrm{TT}$ & $\mathrm{CT}$ & TT & $\mathrm{TT}, \mathrm{CT}$ & $\mathrm{TT}, \mathrm{CT}$ \\
\hline rs2317676 & $\mathrm{AA}$ & GG & $\mathrm{AG}$ & GG & $\mathrm{AG}$ & $\mathrm{GG}, \mathrm{AG}$ & GG & $\mathrm{GG}, \mathrm{AG}$ \\
\hline rs16863323 & $\mathrm{CC}$ & $\mathrm{TT}$ & $\mathrm{CT}$ & CT, TT & $\mathrm{CT}$ & TT & TT & TT, CT \\
\hline OR & $1^{*}$ & 2.83 & 2.26 & 2.12 & 1.31 & 1.28 & 1.05 & 1.08 \\
\hline $95 \% \mathrm{CI}$ & - & $1.35-8.32$ & $1.16-6.48$ & $1.13-5.25$ & $0.94-2.56$ & $0.83-2.02$ & $0.67-1.78$ & $0.79-1.83$ \\
\hline$P$ value & - & 0.002 & 0.022 & 0.033 & 0.196 & 0.433 & 0.627 & 0.538 \\
\hline
\end{tabular}

"The low-risk genotype for each genetic factor was used as the reference OR. OR, odds ratio; CI, confidence intervals.

platelet activation [31]. Some studies have shown $T X A 2 R$ polymorphisms are associated with cerebral infarction and platelet activation [31, 32]. Glycoprotein IIIa and platelet membranes receptors play an important role in platelet activation and arterial thrombosis. The GPIIIa rs2317676 and P2Y12 rs16863323 encode glycoprotein IIIa and platelet membranes receptors, respectively. Fontana et al. [33] has shown that a haplotype of the P2Y12 receptor gene is associated with platelet aggregation. The GPIIIa rs2317676 had an effect on platelet aggregation in acute IS patients [22]. Thus, we reason that interactions among rs1131882, rs2317676 and rs16863323 could provide these individuals with higher platelet activation, thereby increasing the risk for carotid plaque vulnerability.

There has several potential limitations in this study. First, due to the relative small sample size and one-center study. Our findings must be validated in larger and multicenter studies. Second, although we genotyped multiple known functional variants in platelet activation-relevant genes, some rare functional variants were not investigated in this population. Thus, future studies involving a larger set of genetic variants should be detected to elucidate the effects of the full extent of gene-gene interactions on carotid plaque vulnerability pathogenesis. Third, carotid plaque vulnerability was assessed by ultrasound in this study. Although ultrasound can identify carotid plaques and determine the extent of stenosis, HR-MRI may provide more information regarding plaque composition and morphology [8]. Thus, it is necessary to assess carotid plaque vulnerability using HR-MRI, and validate our finding in future. Finally, we aim of present study was to investigate the association between variants in platelet activation-relevant genes and risk for carotid plaque vulnerability. Thus, we did not investigate the relations between these variants and carotid artery stenosis in this study.

\section{MATERIALS AND METHODS}

\section{Study population}

We consecutively enrolled 396 IS patients who had their first strokes and were admitted tothe People's Hospital of Deyang City within $72 \mathrm{~h}$ of the onset of stroke between 
Table 6: Multivariate analysis of the major risk factors for vulnerable plaque

\begin{tabular}{llcc}
\hline Risk factor & $\boldsymbol{O R}^{*}$ & $\mathbf{9 5 \%} \mathbf{C I}$ & $\boldsymbol{P}$ value \\
\hline Hypertension & 1.86 & $1.07-4.09$ & 0.033 \\
Diabetes mellitus & 0.95 & $0.82-1.87$ & 0.288 \\
AT stroke & 0.83 & $0.76-1.52$ & 0.673 \\
Hyperlipidemia & 0.81 & $0.66-1.38$ & 0.712 \\
Platelet aggregation & 0.72 & $0.67-1.17$ & 0.735 \\
Platelet-leukocyte aggregates & 0.83 & $0.79-1.26$ & 0.668 \\
Statins & 0.42 & $0.51-1.08$ & 0.103 \\
Antiplatelet drugs & 0.51 & $0.58-1.12$ & 0.134 \\
TXA2R rs1131882TT & 1.37 & $0.96-3.08$ & 0.092 \\
TXAS1 rs2267679TT & 1.22 & $0.91-2.15$ & 0.178 \\
TXAS1 rs41708TT & 1.33 & $0.93-2.46$ & 0.139 \\
P2Y12 rs16863323TT & 1.37 & $0.95-2.24$ & 0.113 \\
GPIII rs2317676GG & 1.49 & $0.97-3.87$ & 0.081 \\
High-risk interactions & 2.61 & $1.33-7.98$ & 0.005 \\
\hline
\end{tabular}

OR, odds ratios; CI, confidence interval; AT, atherothrombotic.

*OR for Platelet aggregation and Platelet-leukocyte aggregates means per 1- Standard Deviation increase.

Table 7: Effect of high-risk interactive genotypes on platelet aggregation and platelet-leukocyte aggregates

\begin{tabular}{lcccccc}
\hline & \multicolumn{2}{c}{ Platelet aggregation(\%) } & \multicolumn{3}{c}{ Platelet-leukocyte aggregates (\%) } \\
\cline { 2 - 6 } & AA-induced & ADP-induced & Leukocyte & Neutrophil & Monocyte & Lymphocyte \\
\hline High-risk interactive & & & & & & \\
genotypes & & & & & & \\
Yes $(n=92)$ & $90.1 \pm 10.7$ & $88.6 \pm 11.2$ & $25.8 \pm 5.2$ & $26.6 \pm 5.6$ & $27.1 \pm 4.9$ & $26.3 \pm 5.8$ \\
No $(n=304)$ & $83.7 \pm 15.2$ & $84.5 \pm 14.8$ & $23.1 \pm 7.2$ & $23.4 \pm 5.8$ & $23.6 \pm 7.5$ & $24.5 \pm 6.3$ \\
$P$ value & $<0.001$ & 0.008 & $<0.001$ & $<0.001$ & $<0.001$ & 0.009 \\
\hline
\end{tabular}

AA, arachidonic acid; ADP, adenosine diphosphate.

August 2010 and March 2013. IS in all cases was due to AT and SAD according to the Trial of ORG 10172 in the Acute Stroke Treatment classification system [34]. The detailed procedures for the recruitment of IS patients, inclusion criteria and exclusion criteriaweredescribed in our previous article [14]. The healthy volunteers who served as controls were selected from outpatients without history of stroke and carotid plaque as confirmed by medical history as well as physical and laboratory examinations at our center. This study protocol was reviewed and approved by the Ethics Committee of our hospital. Each of the participants provided written informed consent before enrollment into this study. Vascular risk factors, including age, gender, current smoking, alcohol intake, body mass index, history of diabetes mellitus, hypertension and myocardial infarction [MI] were recorded. Fasting blood samples were tested for blood sugar, hemoglobin A1c, triglycerides (TG), total plasma cholesterol (TC), low-density lipoprotein cholesterol (LDL-C), and homocysteine. Hyperlipidemia was defined as $\mathrm{TC}>200 \mathrm{mg} / \mathrm{dL}, \mathrm{TG}>180 \mathrm{mg} / \mathrm{dL}$ or use of lipidlowering medication.

\section{Carotid plaque vulnerability assessment by B-mode ultrasound}

Bilateral common and internal carotid arteries, as well as bifurcations, were examined for atherosclerotic plaque presenceusing a diagnostic ultrasound device (type 512, Acuson Sequoia Apparatus, 7.5-MHz probe, Berlin, Germany) in all patients, according to standard scanning and reading protocols [7]. Assessment of plaque morphology was performed with the use of criteria established at an international consensus meeting on the morphology and risk of carotid plaques [35]. Plaque echogenicity was graded as uniformly anechoic, isoechoic, or hyperechoic; predominantly anechoic, isoechoic, or hyperechoic; or unclassifiable calcific. Plaque surface structure was assessed as smooth, irregular, or ulcerated. According to plaque echogenicity and surface structure, carotid plaque was further classified into I to IV $[14,35]$. Plaque of class I or class II was defined as VP, and plaque of class III or class IV was defined as SP. Plaquemorphology and surface structure were graded independently by both authors 
blinded to patient clinical status. For a test run in this study, we assessed the reproducibility of plaque echogenicity in 33 randomly selected plaques. Intraobserver and interobserver coefficients of variation for plaque echogenicity were $8.2 \%$ and $8.8 \%$, respectively, suggesting relatively reliable measurements in current study. The detailed procedures for evaluating plaques, types of plaques, intraobserver and interobserver coefficients were performed as described in our previous study [14]. According to the results of carotid ultrasonography, the patients were divided into three groups: non-carotid plaque group, VP group and SP group. Furthermore, 40 patients with ultrasound-based carotid plaque were also measured blindly by HR-MRI. Exact agreement of VP was found in $92 \%$ of the cases, and there were no major disagreements. These indicated that carotid ultrasound is a relatively reliable method for assessing carotid plaque vulnerability.

\section{Genotyping}

The 11 SNPs of platelet activation-relevant genes were selected from the NCBI database (http:/www.ncbi. nlm.nih.gov/SNP), according to the criteria: (1) the SNPs had been assessed in previous studies; (2) the SNPs lead to amino acid changes; (3) the SNPs with minor allele frequency $>0.05$; (4) Tagging SNPs across different human populations (http://pga.gs.washington.edu).

Whole blood $(3 \mathrm{~mL})$ was drawn from an arm vein into a sterile tube containing ethylenediaminetetraacetic acid (EDTA) and stored at $-80^{\circ} \mathrm{C}$ until genotype analysis was performed.Genotypes of the 11 variants were examined using matrix-assisted laser desorption ionization timeof-flight mass spectrometry methods as our previously described $[13,14,22]$.

\section{Measurement of platelet activation}

Venous blood $(6 \mathrm{~mL})$ was drawn from an antecubital vein in each patient on admission. Platelet-leukocyte aggregates were measured by FC 500 MPC flow cytometry (Beckman Coulter Ltd, Krefeld, Germany), and we used direct fluorescent markers (all commercially available; Coulter Immunotech, Krefeld, Germany). Platelet aggregation was measured by light transmittance aggregometry. The results of optical platelet aggregometry are presented as the amplitude of light transmittance at five minutes after addition of the agonist $0.5 \mathrm{mM}$ AA and $10 \mu \mathrm{M}$ ADP with a BioData PAPS-4 platelet aggregometer (Helena Laboratories, Beaumont, TX, USA). The procedures for measuring platelet-leukocyte aggregates and platelet aggregation were described in our previous studies [36, 37].

\section{Statistical analysis}

We calculated the sample size, based on a suggested sample size requirement of gene-gene interactions [38].
We calculated that a sample of 180 patients with SP and 100 patients with VP would sufficiently provide $80 \%$ power at the 5\% significance level calculated using three genetic models: the dominant model, the additive model, and the recessive model.

SPSS 16.0 (SPSS Inc., Chicago, IL, USA) was used to perform the statistical analyses. The $\chi^{2}$ test was used to analyze the deviation of Hardy-Weinberg equilibrium for genotype frequencies. Continuous variables were compared using analysis of variance (ANOVA) followed by Student-Newman-Keuls test, and discrete variables were assessed using the $\chi^{2}$ testamong patients with VP, $\mathrm{SP}$ and non-plaque. Difference of genotype frequencies among patients with VP, SP and non-plaque was also compared by $\chi^{2}$-test. Gene-gene interaction was assessed using the GMDR method, as described in our previous studies [21, 24]. The GMDR v 0.7 program was used in this study (www.healthsystem. virginia.edu/internet/ addiction-genomics/Software) [26]. This model was then confirmed by permutation test implemented in the GMDR software. Subsequently, logistic regression analysis was performed to adjust covariate risk factors using variables with $P$ values $<0.05$ in univariate analysis, and previous statins or antiplatelet treatments to assess the independent contribution of the variants and interactions among these variants on carotid plaque vulnerability, and odds ratio (OR) with 95\% confidence intervals (CI) were calculated. All tests were two sided, and the threshold level of $P<0.05$ denoted statistical significance.

\section{CONCLUSIONS}

In present study, the 11 variants in platelet activation-relevant genes were not associated with risk of carotid plaque vulnerability after adjusting for potential confounding variables. However, the GMDR analysis showed that there were synergistic effects of gene-gene interactions among TXA2Rr s1131882, GPIIIa rs2317676 and $P 2 Y 12$ rs16863323 on carotid plaque vulnerability risk. However, our current findings are needed to be validated in future studies.

\section{Abbreviations}

IS: ischemic stroke; TXA2: thromboxanesA2; TXAS: thromboxane synthase; GPIIb: glycoprotein IIb; GPIIIa:glycoprotein IIIa; TXA2R; thromboxanesA2receptor; P2Y12: platelet membranes receptors; SNPs: single nucleotide polymorphisms; GMDR: generalized multifactor dimensionality reduction; AT: atherothrombotic; SAD: small artery disease; MI: myocardial infarction; TC: total cholesterol; TG: triglycerides; LDL-C: low-density lipoprotein cholesterol; VP: vulnerable plaque; SP: stable plaque; AA: arachidonic acid; ADP: adenosine diphosphate; OR: odds ratio; $\mathrm{CI}$ : confidence interval. 


\section{Author contributions}

Xingyang Yi participated in the design of the study and drafted the manuscript. Jing Lin participated in statistical analysis and drafted the manuscript. Hua Luo carried out the molecular genetic studies, participated in the sequence alignment. Ju Zhou helped to draft the Tables. Yanfeng Wang participated in carotid ultrasonography. Qiang Zhou and Chun Wang helped to draft the manuscript. All authors read and approved the final manuscript.

\section{ACKNOWLEDGMENTS}

None.

\section{Ethics statement}

The study protocol was approved by the Ethics Committee of the People's Hospital of Deyang City. Written informed consent was obtained from each patient prior to study enrollment.

\section{CONFLICTS OF INTEREST}

The authors declare no conflicts of interest.

\section{FUNDING}

This study was supported in part by grants from the Scientific Research Foundation of Sichuan Provincial Health Department (Grant No.16ZD046) and Scientific Research Foundation of Chengdu University of Traditional Chinese Medicine (Grant No.YYZX1510).

\section{REFERENCES}

1. Wang YL, Wu D, Liao X, Zhang W, Zhao X, Wang YJ. Burden of stroke in china. Int J Stroke. 2007; 2:211-213.

2. Wei JW, Heeley EL, Wang JG, Huang Y, Wong LK, Li Z, Heritier S, Arima H, Anderson CS. Comparison of recovery patterns and prognostic indicators for ischemic and hemorrhagic stroke in China: the China QUEST (QUality Evaluation of Stroke Care and Treatment) Registry study. Stroke. 2010; 41:1877-1883.

3. Donnan GA, Fisher M, Macleod M, Davis SM. Stroke. Lancet. 2008; 371:1612-1623.

4. Deb P, Sharma S, Hassan KM. Pathophysiologic mechanisms of acute ischemic stroke: An overview with emphasis on therapeutic significance beyond thrombolysis. Pathophysiology. 2010; 17:197-218.

5. Momjian-Mayor I, Kuzmanovic I, Momjian S, Bonvin C, Albanese S, Bichsel D, Comelli M, Pereira VM, Lovblad KO, Sztajzel RF. Accuracy of a novel risk index combining degree of stenosis of the carotid artery and plaque surface echogenicity. Stroke. 2012; 43:1260-1265.

6. Mathiesen EB, Bonaa KH, Joakimsen O. Echolucent plaques are associatedwith high risk of ischemic cerebrovascular events in carotid stenosis:the Tromso study. Circulation. 2001; 103:2171-2175.

7. Rundek T, Arif H, Boden-Albala B, Elkind MS, Paik MC, Sacco RL. Carotid plaque, a subclinical precursor of vascular events: the Northern Manhattan Study. Neurology. 2008; 70:1200-1207.

8. Fitzpatrick LA, Berkovitz N, Dos Santos MP, Majeed N, Glikstein R, Chakraborty S, Veinot JP, Stotts G, Berthiaume A, Chatelain R. Vulnerable carotid plaque imaging and histopathology without a dedicated MRI receiver coil. Neuroradiol J. 2017; 30:120-128.

9. Gronholdt ML, Nordestgaard BG, Schroeder TV, Vorstrup S, Sillesen H. Ultrasonic echolucent carotid plaques predict future strokes. Circulation. 2001; 104:68-73.

10. von Reutern GM, Goertler MW, Bornstein NM, Del Sette M, Evans DH, Hetzel A, Kaps M, Perren F, Razumovky A, von Reutern M, Shiogai T, Titianova E, Traubner P, et al. Grading carotid stenosis using ultrasonic methods. Stroke. 2012; 43:916-921.

11. AbuRahma AF, Wulu JT Jr, Crotty B. Carotid plaque ultrasonic heterogeneity and severity of stenosis. Stroke. 2002; 33:1772-1775.

12. Gardener H, Beecham A, Cabral D, Yanuck D, Slifer S, Wang L, Blanton SH, Sacco RL, Juo SH, Rundek T. Carotid plaque and candidate genes related to inflammation and endothelial function in Hispanics from northern Manhattan. Stroke. 2011; 42:889-896.

13. Yi X, Lin J, Luo H, Wang C, Liu Y. Genetic variants of PTGS2, TXA2R and TXAS1 are associated with carotid plaque vulnerability, platelet activation and TXA2 levels in ischemic stroke patients. PLoS One. 2017; 12:e0180704.

14. Yi XY, Liao DX, Wang C, Cheng W, Fu XQ, Zhang B. Cytochrome P450 Genetic Variants and Their Metabolite Levels Associated with Plaque Stability in Patients with Ischemic Stroke. J Atheroscler Thromb. 2016; 23:330-338.

15. Lavallée PC, Labreuche J, Faille D, Huisse MG, NicaiseRoland P, Dehoux M, Gongora-Rivera F, Jaramillo A, Brenner D, Deplanque D, Klein IF, Touboul PJ, Vicaut E, et al. Circulating Markers of Endothelial Dysfunction and Platelet Activation in Patients with Severe Symptomatic Cerebral Small Vessel Disease. Cerebrovasc Dis. 2013; 36:131-138.

16. Toghi H, Suzuki H, Tamura K, Kimura B. Platelet volume, aggregation, and adenosine triphosphate release in cerebral thrombosis. Stroke. 1991; 22:17-22.

17. Kernan WN, Ovbiagele B, Black HR, Bravata DM, Chimowitz MI, Ezekowitz MD, Fang MC, Fisher M, Furie KL, Heck DV, Johnston SC, Kasner SE, Kittner SJ, et al. Guidelines for the prevention of stroke in patients with stroke and transient ischemic attack: a guideline 
for healthcare professionals from the American Heart Association/American Stroke Association. Stroke. 2014; 45:2160-2236.

18. Catellier DJ, Aleksic N, Folsom AR, Boerwinkle E. Atherosclerosis Risk in Communities (ARIC) Carotid MRI flow cytometry study of monocyte and platelet markers: intraindividual variability and reliability. Clin Chem. 2008; 54:1363-1371.

19. Fateh-Moghadam S, Li Z, Ersel S, Reuter T, Htun P, Plockinger U, Bocksch W, Dietz R, Gawaz M. Platelet degranulation is associated with progression of intimamedia thickness of the common carotid artery in patients with diabetes mellitus type 2. Arterioscler Thromb Vasc Biol. 2005; 25:1299-1303.

20. Dorsam RT, Kunapuli SP. Central role of the $\mathrm{p} 2 \mathrm{y} 12$ receptor in platelet activation. J Clin Invest. 2004; 113:340-345.

21. Floyd CN, Ferro A. The platelet fibrinogen receptor: From megakaryocyte to the mortuary. JRSM Cardiovasc Dis. 2012; 1:1-13. https://doi.org/10.1258/cvd.2012.012007.

22. Yi X, Lin J, Wang Y, Zhou J, Zhou Q. Interaction among CYP2C8, GPIIIa and P2Y12 variants increase susceptibility to ischemic stroke in Chinese population. Oncotarget. 2017; 8:70811-70820. https://doi.org/10.18632/oncotarget.19991.

23. Li Q, Chen BL, Ozdemir V, Ji W, Mao YM, Wang LC, Lei HP, Fan L, Zhang W, Liu J, Zhou HH. Frequency of genetic polymorphisms of COX1, GPIIIa and P2Y1 in a Chinese population and association with attenuated response to aspirin. Pharmacogenomics. 2007; 8:577-586.

24. Floyd CN, Ferro A. The P1A1/A2 polymorphism of glycoprotein IIIa in relation to efficacy of antiplatelet drugs: a systematic review and meta-analysis. Br J Clin Pharmacol. 2014; 77:446-457.

25. Yi X, Zhou Q, Wang C, Lin J, Liu P, Fu C. Platelet receptor Gene (P2Y12, P2Y1) and platelet glycoprotein Gene (GPIIIa) polymorphisms are associated with antiplatelet drug responsiveness and clinical outcomes after acute minor ischemic stroke. Eur J Clin Pharmacol. 2017; 73:437-443.

26. Lou XY, Chen GB, Yan L, Ma JZ, Zhu J, Elston RC, Li MD. A generalized combinatorial approach for detecting gene-by-gene and gene-by-environment interactions with application to nicotine dependence. Am J Hum Genet. 2007; 80:1125-1137.

27. Yi X, Lin J, Wang C, Huang R, Liu Y. Interactions among Variants in Eicosanoid Genes Increase Risk of Atherothrombotic Stroke in Chinese Populations. J Stroke Cerebrovasc Dis. 2017; 26:1773-1780.
28. Yi X, Han Z, Zhou Q, Lin J, Wang C. Interactions among COX-2, GPIIIa and P2Y1 variants are associated with aspirin responsiveness and adverse events in patients with ischemic stroke.Ther Adv Neurol Disord. 2017; 10:161-170.

29. Bevan S, Traylor M, Adib-Samii P, Malik R, Paul NL, Jackson C, Farrall M, Rothwell PM, Sudlow C, Dichgans M, Markus HS. Genetic heritability of ischemic stroke and the contribution of previously reported candidate gene and genomewide associations. Stroke. 2012; 43:3161-3167.

30. Culverhouse R, Suarez BK, Lin J, Reich T. A perspective on epistasis: Limits of models displaying no main effect. Am J Hum Genet. 2002; 70:461-471.

31. Park SA, Park BL, Park JH, Lee TK, Sung KB, Lee YK, Chang HS, Park CS, Shin HD. Association of polymorphisms in thromboxane A2 receptor and thromboxane A synthase 1 with cerebral infarction in a Korean population. BMB Rep. 2009; 42:200-205.

32. Zhao J, Zheng L, Fei Q, Fu Y, Weng Y, Wu H, Li H, Jun Q, Shao J, Xu Y. Association of thromboxane A2 receptor gene polymorphisms with cerebral infarction in a Chinese population. Neurol Sci. 2013; 34:1791-1796.

33. Fontana P, Dupont A, Gandrille S, Bachelot-Loza C, Reny JL, Aiach M, Gaussem P. Adenosine diphosphateinduced platelet aggregation is associated with P2Y12 gene sequence variations in healthy subjects. Circulation. 2003; 108:989-995.

34. Han SW, Kim SH, Lee JY, Chu CK, Yang JH, Shin HY, Nam HS, Lee BI, Heo JH. A new subtype classification of ischemic stroke based on treatment and etiologic mechanism. Eur Neurol. 2007; 57:96-102.

35. De Bray JM, Baud JM, Dauzat M. Consensus concerning the morphology and the risk of carotid plaques. Cerebrovasc Dis. 1997; 7:289-296.

36. Yi X, Wang C, Liu P, Fu C, Lin J, Chen Y. Antiplatelet drug resistance is associated with early neurological deterioration in acute minor ischemic stroke in the Chinese population. J Neurol. 2016; 263:1612-1619.

37. Yi X, Lin J, Wang C, Zhang B, Chi W. A comparative study of dual versus monoantiplatelet therapy in patients with acute large-artery atherosclerosis stroke. J Stroke Cerebrovasc Dis. 2014; 23:1975-1981.

38. Wang S, Zhao H. Sample size needed to detect gene-gene interactions using association designs. Am J Epidemiol. 2003; 158:899-914. 